\title{
Design of Flexible Structural System for Building Customization
}

\author{
Diego Lozano, Ángel Martín (D), Miguel A. Serrano (D), and Carlos López-Colina \\ Department of Construction, University of Oviedo, Campus de Gijón, Gijón, Spain \\ Correspondence should be addressed to Ángel Martín; martinangel@uniovi.es
}

Received 22 February 2019; Revised 2 May 2019; Accepted 5 May 2019; Published 16 June 2019

Academic Editor: Pier Paolo Rossi

Copyright (C) 2019 Diego Lozano et al. This is an open access article distributed under the Creative Commons Attribution License, which permits unrestricted use, distribution, and reproduction in any medium, provided the original work is properly cited.

\begin{abstract}
The main aim of this research work is to design a structural system for building customization, through simple industrialized components. The system is able to adapt to different orthogonal geometries and presents the necessary flexibility to allow modifications over the structure of the building throughout its life. The so-named "flexible structural system" (FSS) is characterized by using only small industrialized components, handled by one person, which exhibit an easy and simple assembly. The new system proposes the use of just two different pieces named basic units (BUi) with only two possible thicknesses for any of them. The system is composed of only 5 different pieces. The generating process of the structural system is based on different combinations of the basic units (BUi) to obtain resistant members (RMn). These resistant members allow to build structural frames (F), and finally, the addition of structural frames allows to generate diaphanous volumes (DV) and obtain the desired structure for the building. The limit of structural length is set at 4.8 meters. Finally, an example is shown where a structure for a diaphanous volume is obtained, using the referred industrialized elements. This shows that the system is systematic and easy to understand by users. We want the users themselves to design and build their own home as well as make the necessary modifications throughout the useful life of the building. This is the final objective.
\end{abstract}

\section{Introduction}

1.1. Introduction to Industrialized Construction Level: Two Headings. Today's society has a clear trend to consume products manufactured in large quantities and therefore relatively inexpensive, but at the same time, the option of customizing these products (mass customization) is also increasing. The actual society no longer recognizes a "long useful life" for products, but rather the fulfillment of a life cycle perfectly adapted to a particular product. In this life cycle, variables such as the continuously changing trends, the economy, or the fashion have influence, in addition to the innate quality of the product itself [1].

There is currently a global market; therefore, products manufactured in a specific place can be used anywhere in the world. So, if someone intends to design products to be used by consumers in remote places [2], sometimes with different cultures, they will find it really difficult especially if they wish to introduce a customization criterion [3].

In a general design process, it may be of great interest to introduce the concept of "do it yourself" [4] since this approach will allow that the consumer by himself is involved as a basic part of the product creation process and thus to achieve that desired customization.

The starting point is the assumption that we are pleased to create, or as Johan Huizinga [5] said, "the instinct play to build, this must be the great incentive to explode in the twenty-first century." So, we are delighted to be able to use products whose final design has been made by ourselves, but at the same time, we also want that this process of "creation" is very simple, easy, and cheap [6].

It is considered that the instinct "play to build" must be the great incitement to be exploited in the twenty-first century. Nowadays, there are some clear samples of this trend, and it can be seen that some very well-known companies like IKEA [7] and LEGO have perfectly assumed this idea and their main stream is based on this "do it yourself."

If these concepts are moved to the construction scope, the self-construction concept can be established as a process by which we could build our own homes, or at least some parts of them, with a high degree of customization, at a reasonable 
price and, very importantly, being easy to assemble. This concept would require the use of industrialized components that present the characteristic of "ready to assemble."

With this research, it is intended to make flexible and to extend the self-construction concept not only to reach the self-manufactured housing but also to be able to convert the housing over the time to adapt it into the specific needs during its life cycle. A relationship between the user and his home is created that reflects his character and suits better the needs at each moment. Then, at this very moment, a new form of housing will be imagined.

\subsection{Proposal of a Global System for Flexible Construction to Industrialized Construction}

1.2.1. Objective. The main aim is to be able to build a building using industrialized components [8], whose assembly can be performed by the own users allowing them adapting to their future needs throughout the life cycle of the aforementioned construction.

Obviously, it is necessary to define some limitations regarding the proposed Global System for Flexible Construction, in such a way that its conception is more practical, systematic, and approachable. These limitations are as follows:
(i) Buildings with 1 or 2 floors
(ii) Low or medium live loads
(iii) Maximum span of 4.8 meters
(iv) Maximum height of 3 meters by storey

The potential use of these buildings could be as follows:
(i) Buildings residential
(ii) Temporary and/or seasonal buildings
(iii) Educational buildings
(iv) Health building
(v) Other uses: singular buildings

1.2.2. General Requirements of the Global System of Flexible Construction. The aim is to design a building system based on the following characteristics:

(1) Set of independent components clearly defined [9] (product catalog)

(2) Countless possible combinations between these components

(3) Easy and systematic assembly and disassembly

(4) Dry construction

(5) Unskilled labour; ready to assemble [10]

(6) Light and easy to handle by one or two persons

(7) Execution following a basic instruction manual (friendly computer app)

The general concept of the Global System of Industrialized Construction is based on the following: "Using a finite set of different industrialized components, with assembly compatibility between them, we can combine them $n$-times to obtain the desired construction."

1.2.3. Spatial Modelling. For the development of this system, the starting point is a modelling according to which each and every one of the proposed buildings will be associated with a volume orthohedron (orthogonal parallelepiped) or set of orthohedrons that may be interacting with each other (Figure 1).

The orthohedron will be limited by an outer covering supported by a structural system (SSF) and with a diaphanous and empty interior "shoe box."

This modelling in orthohedrons allows obtaining the following geometric characteristics:

(i) 6 faces that always will be rectangular

(ii) 8 equal corners

(iii) 12 equal edges

(iv) Angles of $90^{\circ}$ in all plane intersections

On each of the 6 proposed faces of a primitive orthohedron, it is possible to attach some new orthohedrons, to obtain an addition of volumes that will constitute the required building.

A new premise is added to these orthohedrons, according to which the dimensions will follow a dimensional order based on a $6 \mathrm{M}$ modulation $(\mathrm{M}=100 \mathrm{~mm})[11,12]$.

1.2.4. Dividing the Global System of Industrialized Construction in Specific Systems. Taking into account the great complexity of the elements that may appear in an entire building, it seems reasonable to divide this Global System for Flexible Construction into several more specific systems, and they can be found for

(1) Foundations (Spain; patent no: ES 2568328 B2)

(2) Flexible structural system

(3) External board-external wall coverings

(4) Internal board-internal wall coverings

(5) Roof (Spain; patent no: ES 2610203 B2)

(6) Spaces and pipes for facilities

(7) Stairs

(8) Removable walls

(9) Connections and seals

(10) Etc.

A basic condition is required that all the specific systems described are interrelated, so that as a whole, they constitute a global system. Therefore, the dimension of modular and dimensional coordination will be maintained in all of them with a value of $6 \mathrm{M}[12,13]$.

The main aim of this work is the design of the flexible structural system.

\section{Flexible Structural System}

2.1. Proposal of the Flexible Structural System. Possibly in the traditional construction, the structural system has been 


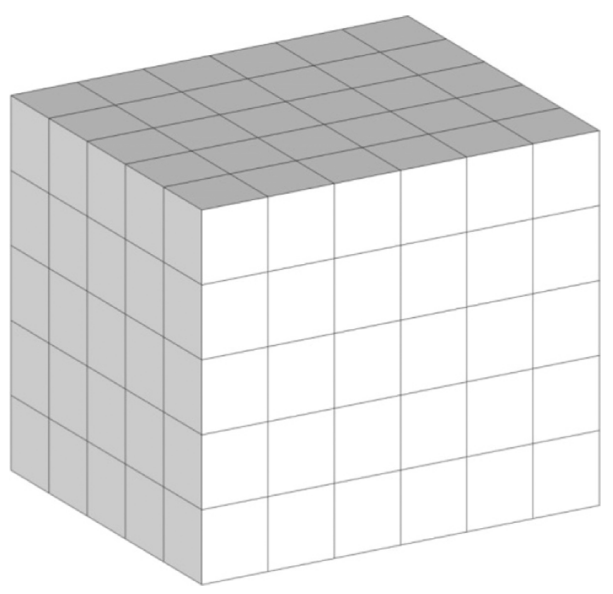

(a)

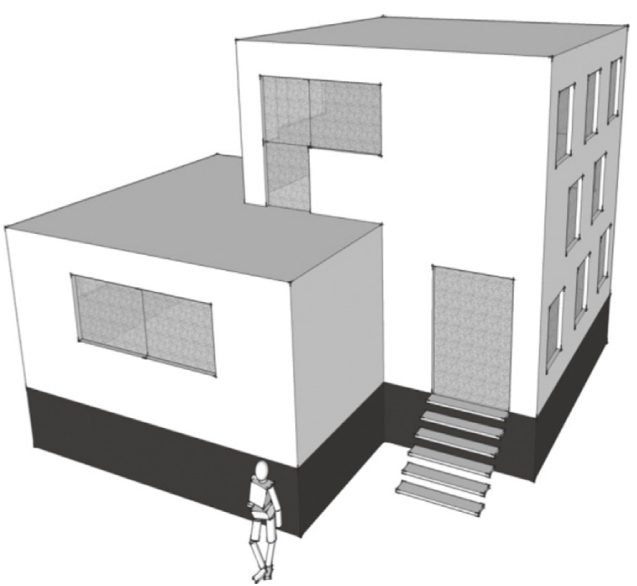

(b)

FIGURE 1: Model of building generated by orthohedrons (orthogonal parallelepipeds). (a) Orthohedron with spatial grid modulated to 6M. (b) Building modelling.

conceived as something totally static and invariable in time, throughout the life of a building. Now it is the moment to try to break this barrier.

The flexible structural system (FSS) emerges as a solution to the attempt of obtaining a structural system that supports a great adaptation to multiple constraints of volumetric design, as well as the possibility of making easy and affordable changes in the structure of a building, throughout its life [14].

The adaptation of the structural scheme to the use variations is the main characteristic of the proposed system, and therefore, it is the idea that this work would wish to transmit [15].

This structural flexibility is conceived as the ability to

(1) To create many different volumes structurally related

(2) To be able to increase or reduce the current volumes

(3) Easy assembly and disassembly of any industrialized component

(4) To be able to execute an opening on walls and floors in the defined volume:

(a) Vertical wall: doors and windows

(b) Horizontal floor: opening for stairs

(5) To generalize the connection systems

(6) To design the minimum number of different industrialized components

(7) To use light components at a human scale (manageable by one or two people)

In general, the design of a new building project requires initially to define a structural typology (including the foundation system) to continue later with other industrialized elements of each of the specific systems commented above.

However, it is important to note that thanks to the structural system the master lines of construction are drawn, allowing defining and establishing the volumes. Therefore, a good design of the flexible structural system (FSS) will determine the success or failure of the proposed new constructive method.
The dimensions of the components of the flexible structural system follow a dimensional order based on a modulation $6 \mathrm{M}(\mathrm{M}=100 \mathrm{~mm})$.

2.2. Specific Background for the Flexible Structural System. Having a look on general industry and more specifically on the construction of industrial storage systems, it can be seen that there are industrial shelving systems that present very peculiar characteristics that are interesting for the construction industrialization (Figure 2) and are of great interest for this research work.

The systems of industrial shelves generally consist of the use of a few steel members, as beams and columns, allowing many assemblies among them through connectors with the aim of constituting a storage system. One of the most interesting characteristics is that they allow storage adapted to the needs of the required industrial activity [16].

Among the general characteristics that can be highlighted for these storage systems are as follows:

(i) Finite and small set of different industrialized components

(ii) Adaptability to volumes

(iii) Joint simplicity

(iv) Lightweight components

(v) Ease of assembly and disassembly

In addition, these systems of shelving have evolved to become a single system for both the storage part and the structural system of the building. This concept is already known as self-supporting systems (Figure 3 ).

These concepts of industrial shelving have been one of the sources of inspiration for the proposal of the flexible structural system.

2.3. Main Characteristics of the Flexible Structural System (FSS). The main characteristic of the FSS is that it uses the same structural profile for any generation of a structural 


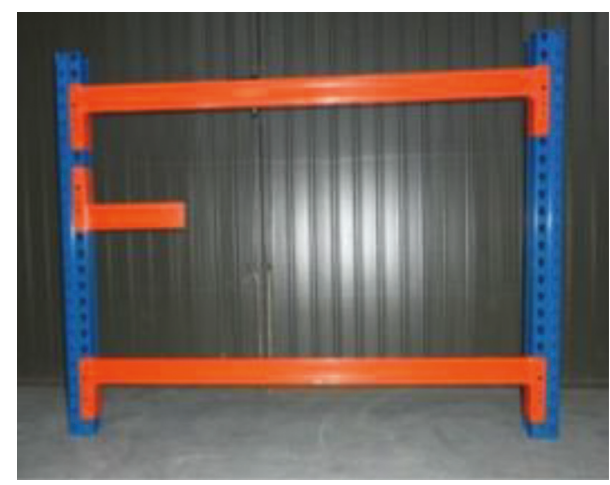

FIgURE 2: Structural flexibility with shelving systems.

model, maintaining constant the external cross section of the profile (Figure 4). This characteristic allows and facilitates all the required assemblies.

Furthermore, an optimization of the required structural material is achieved by just varying the thickness of the profiles. However, to cover the intention of the system's versatility, only 2 thicknesses of profiles are proposed, since increasing their number would make assembly difficult for nonskilled people. The most suitable material to comply with these characteristics is the coldformed steel profiles.

The general conception of the flexible structural system (FSS) is based on establishing a series of staggered concepts, so that starting from a pair of initial components, which will be named structural generating couple and combining them, diaphanous volumes may be created.

The staggered concepts to be established and developed are as follows:

(1) Structural generating couple (2 basic units)

(2) Member resistant

(3) Frames (wall frames and beam frames)

(4) Diaphanous volume

(5) Structural scheme for the diaphanous volume

2.3.1. Geometry of the Proposed Profile. The proposed section is a square one with longitudinal channels in any external face and with the external dimensions of $120 \times 120 \mathrm{~mm}$ (Figure 4).

The section arises as a result of trial and error after considering many combinations, where the easy connection of different components was a priority, as well as their easy coupling and decoupling within a structural scheme already defined and seeking that the interference between components was minimal. Another priority was to do it with a reduced number of pieces to make the system as versatile as possible.

The bigger difficulties arise in situations of dismantling and especially in singular points such as corners and both external and internal edges. Finally, after many proofs, the final design for the cross section was reached. Figure 4 shows this proposed cross section.

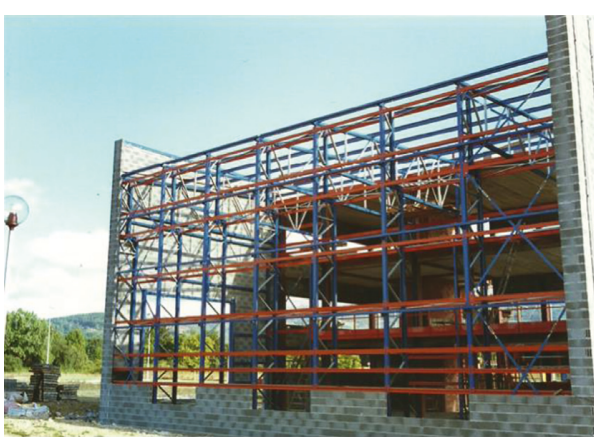

Figure 3: Structural system of self-supporting shelves for the construction of a building.

2.3.2. Material Optimization. In general, given the different demands of building actions (self-weights, live loads, wind, etc.), the different structural elements will require optimizing their section. As the FSS had imposed that the external dimensions of the profile will be kept constant, only the thickness of the profile may be modified. In order to not to extend the final number of pieces and to simplify the execution process, only two thicknesses are proposed:

(i) Small thickness $=2.0 \mathrm{~mm}$ denoted by green colour

(ii) Big thickness $=3.0 \mathrm{~mm}$ denoted by red colour

It is a little bit "rough" optimization at a structural level, but for the flexible structural system, the simplicity of components and their easy assembly must be more important than to handle a high number of different pieces with different thicknesses although more optimized structurally speaking.

This paper is focused on the conceptual design of the proposed system; therefore, some data, such as those related to thickness, are derived from initial calculations that are included in section 4.3. It is worth to mention that the whole research is in progress, and the next step is to prepare a fullscale prototype including the connections, that will be experimentally tested in the laboratory to verify the reliability of the system and, if necessary, to correct it to achieve its viability. The test results also will help to validate the numerical model that will allow, if necessary, to carry out more precise calculations.

2.3.3. Qualitative Characteristics of the Proposed Profile. The most important qualitative characteristics of the profile are as follows:

(1) Easy to Manufacture. The profiles will be manufactured in cold-formed steel following an ordinary forming process to obtain the desired cross section. Despite being a hollow section, its shape is not complex to be manufactured since the current folding technology allows producing these in continuous and fast processes. This easy manufacturing process will allow cost reduction.

(2) The optimization of structural sections is achieved varying the wall thicknesses of components for the resistant members. As commented above, just two 


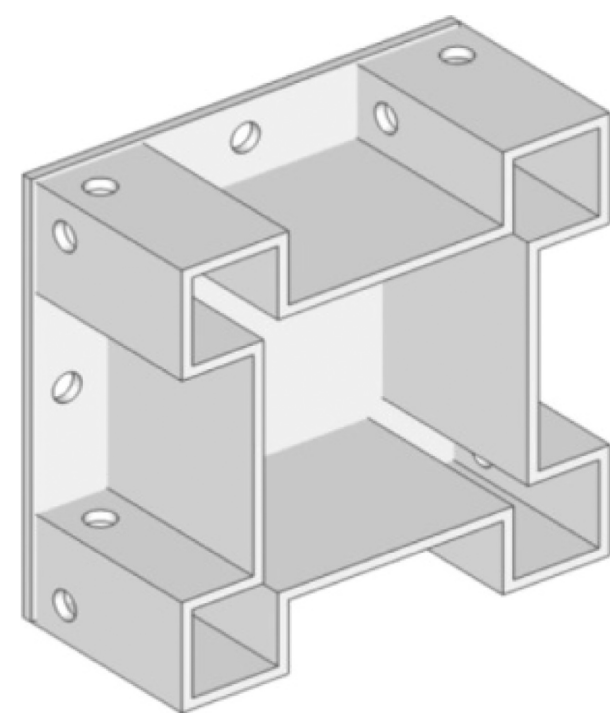

(a)

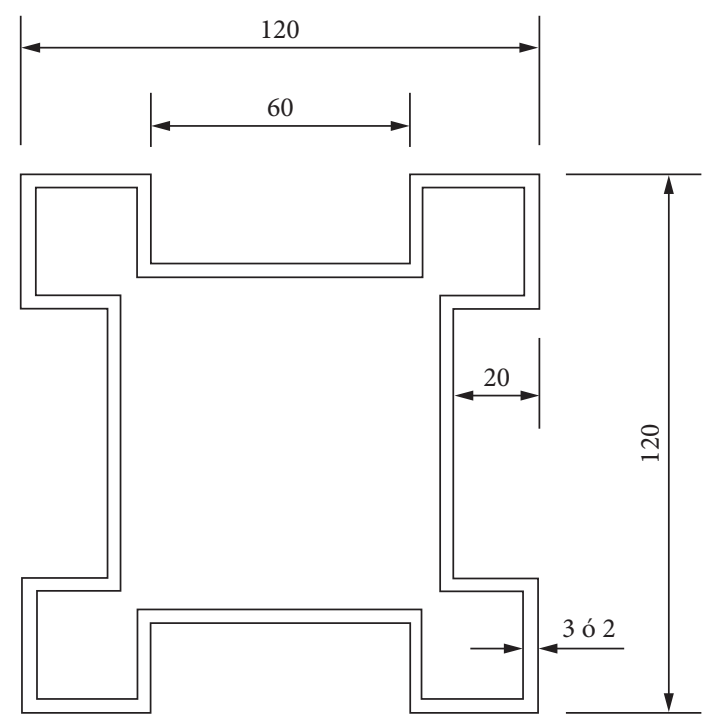

(b)

Figure 4: (a) Proposed cross section. (b) External dimensions $120 \times 120 \mathrm{~mm}$.

thicknesses are proposed while the outside dimensions of the cross section remain constant.

(3) The Possibility to Use the 4 Faces of the Profile. It is possible to attach different elements by an easy assembly over the 4 faces. This allows creating orthogonal 3D structures.

(4) Easy to Assemble. The longitudinal outer channels in the proposed cross section allow inserting the connection pieces, making it easy to form a plane joint among the components.

\section{Components of the Flexible Structural System}

3.1. Structural Generating Couple, Basic Units (BUi). It is proposed a structural generator unit that is composed of two industrialized components that will be named "basic units," BU1 and BU2 (Figure 5).

The basic unit 1 (UB1) has the mentioned cross section, and its length equals $24 \mathrm{M} / 5(480 \mathrm{~mm})$ with $\mathrm{M}=100 \mathrm{~mm}$ (ISO 1040 UNE 41604: 1997).

The basic unit 2 (UB2) has the same cross section, but its length is just $3 \mathrm{M} / 5(60 \mathrm{~mm})$.

These two basic units UB1 and UB2 present the same cross section, and their external dimensions are kept constant. In addition to complete these basic units, the profiles include plates that are connected by welds on both ends of them (Figure 6).

The plates present several holes in the middle of any of the four sides near to their edges that will allow the connection between these basic units.

Thus, the proposal of the flexible structural system consists of having only these two simple elements that admit the possibility of a great number of combinations allowing generating the structural scheme for a building.

Furthermore, as commented above, it is intended to optimize the cross sections using just two thicknesses. According to this, the flexible structural system (FSS) only would require 4 different industrialized components (Figure 7):

Basic unit 1 (BU1) thickness $t=2 \mathrm{~mm}$, green colour

Basic unit 1 (BU1) thickness $t=3 \mathrm{~mm}$, red colour

Basic unit 2 (BU2) thickness $t=2 \mathrm{~mm}$, green colour

Basic unit 2 (BU2) thickness $t=3 \mathrm{~mm}$, red colour

The described basic units allow the longitudinal direct assembly by means of joints with mechanical fasteners. The joint is very simple both in the assembly and disassembly process (Figure 8 ).

3.2. Resistant Member (RMn). Now, a new concept denoted "Resistant Member" (RMn) is introduced. It can be defined as a specific and systematic combination of different basic units (BUi). This combination is not random, but making a series of predetermined combinations will allow to obtain a modulated length. The connection of the basic units to form resistant members is carried out longitudinally to the basic units.

The flexible structural system proposes the use of 10 resistant members that are denoted as follows: $(\mathrm{RMn})=(\mathrm{RM} 1),(\mathrm{RM} 2) . .(\mathrm{RM} 10)$.

These resistant members will have a length determined by the values of an arithmetic progression:

$$
a_{n}=a_{1}+(n-1) d,
$$

where $a_{n}=$ general term of the series, $a_{1}=24 \mathrm{M} / 5$, first term of the series, $n=1,2,3, \ldots, 10$, and $d=$ incremental value of $6 \mathrm{M}$.

So the corresponding arithmetic progression will be

$$
a_{n}=\frac{24 \mathrm{M}}{5}+(n-1) 6 \mathrm{M}=480+(n-1) 600 .
$$

The first term of the series corresponds to the basic unit 1 (BU1) with a length of $480 \mathrm{~mm}$ that is $24 \mathrm{M} / 5$. 


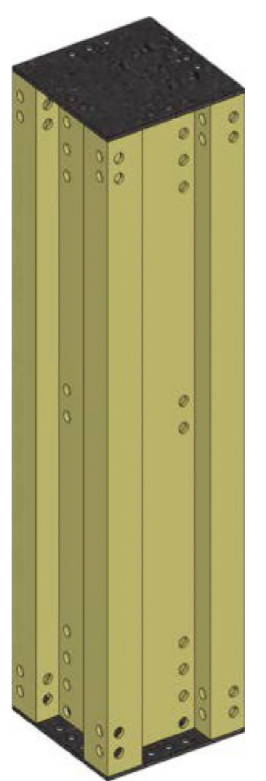

(a)

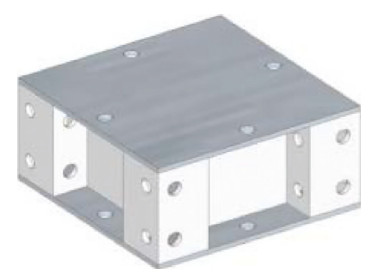

(b)

FIgURE 5: Structural generating couple. (a) Basic unit BU1, length $480 \mathrm{~mm}$; (b) basic unit BU2, length $60 \mathrm{~mm}$.

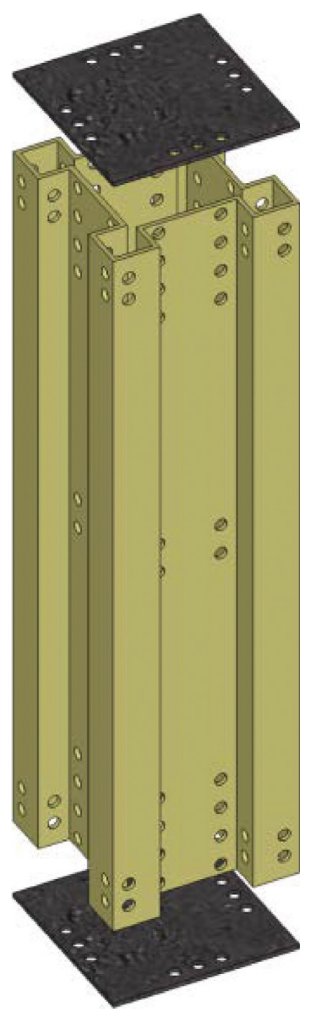

(a)

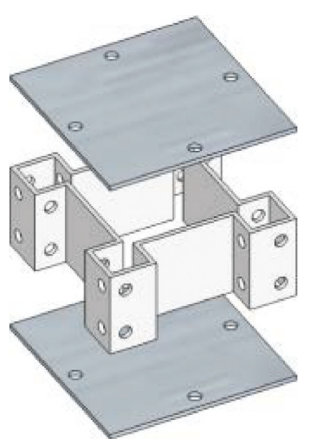

(b)

FIgURE 6: Forming the basic units: profile and closing plates.

In the proposed flexible structural system, only the 8 first values of the arithmetic series are considered. So, one of the initial hypotheses that consisted of fixing the maximum span to 4.8 meters is being introduced.
The following terms of the series correspond with the values of lengths for the 8 resistant members (RMn) that are considered:
(i) $\mathrm{RM1}=480 \mathrm{~mm}$
(ii) $\mathrm{RM} 2=1080 \mathrm{~mm}$
(iii) $\mathrm{RM} 3=1680 \mathrm{~mm}$
(iv) $\mathrm{RM} 4=2280 \mathrm{~mm}$
(v) RM5 $=2880 \mathrm{~mm}$
(vi) RM6 $=3480 \mathrm{~mm}$
(vii) $\mathrm{RM7}=4080 \mathrm{~mm}$
(viii) $\mathrm{RM} 8=4680 \mathrm{~mm}$

It can be seen (Figure 9) that these resistant members are obtained by the addition of different basic units maintaining a rhythm of placement.

This rhythm of placement consists of adding to the previous resistant member (RMn) two basic units 2 (BU2), plus one basic unit 1 (BU1), and so on. This can be written as

$$
\begin{aligned}
(\mathrm{RM} 1)= & 1(\mathrm{UB} 1), \\
(\mathrm{RM} 2)= & 1(\mathrm{UB} 1)+2(\mathrm{UB} 2)+1(\mathrm{UB} 1) \\
= & 2(\mathrm{UB} 1)+2(\mathrm{UB} 2), \\
(\mathrm{RM} 3)= & 1(\mathrm{UB} 1)+2(\mathrm{UB} 2)+1(\mathrm{UB} 1)+2(\mathrm{UB} 2) \\
& +1(\mathrm{UB} 1)=3(\mathrm{UB} 1)+2(2(\mathrm{UB} 2)), \\
(\mathrm{RM} 4)= & 1(\mathrm{UB} 1)+2(\mathrm{UB} 2)+1(\mathrm{UB} 1)+2(\mathrm{UB} 2) \\
& +1(\mathrm{UB} 1)+2(\mathrm{UB} 2)+1(\mathrm{UB} 1)=4(\mathrm{UB} 1) \\
& +3(2(\mathrm{UB} 2)) .
\end{aligned}
$$

In a general way, it can be established that a resistant member " $n$ " (RMn) is going to be formed by the following basic units:

$$
\left(\mathrm{RM}_{n}\right)=n\left(\mathrm{UB}_{1}\right)+(n-1)\left(2\left(\mathrm{UB}_{2}\right)\right)
$$

It is easy to probe that a resistant member " $n$ " will need " $n$ " basic units 1 and " $2(n-1)$ " basic units 2 .

The " $n$ " number corresponds to the number of resistant members and may be $n=1,2, \ldots, 8$ (Figure 9).

It is important to highlight that these resistant members (RMn) will allow forming frames and will be able to be used both as columns and beams.

3.3. Joint Components. Once a system of resistant members is established, a joining system is needed that allows to carry out all the connections and disconnections in an easy and safe way. So some simple connections are going to be proposed. This will consist of holes on which through screws can be put through the holes and also some special pieces that facilitate the joint system among orthogonal structural components.

The proposed connections for the flexible structural system are as follows: 


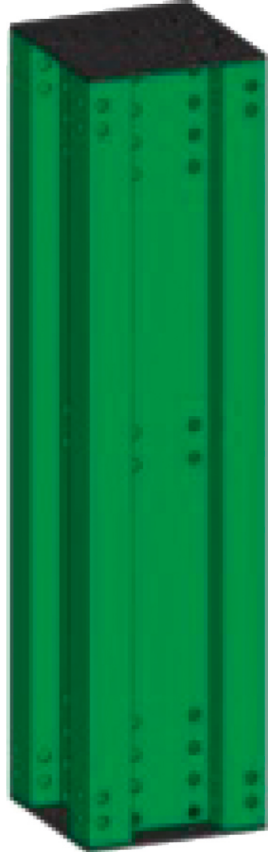

(a)

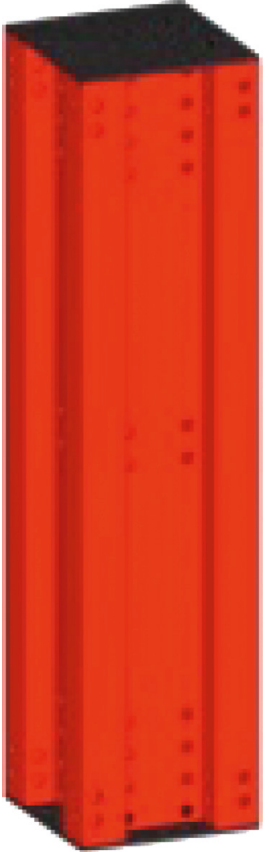

(b)
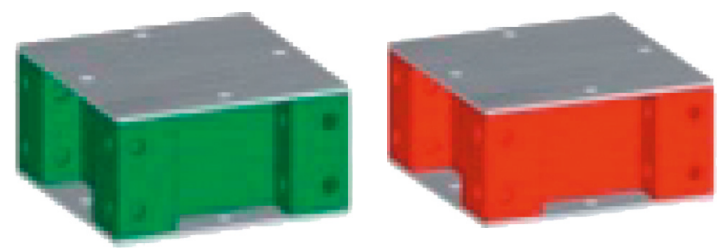

(c)

Figure 7: Basic units, BU1 and BU2, with different colours depending on their thickness. BU1: (a) $t=2 \mathrm{~mm}$ (green colour) and (b) $t=3 \mathrm{~mm}$ (red colour); BU2: (c) $t=2 \mathrm{~mm}$ (green colour) and (d) $t=3 \mathrm{~mm}$ (red colour).

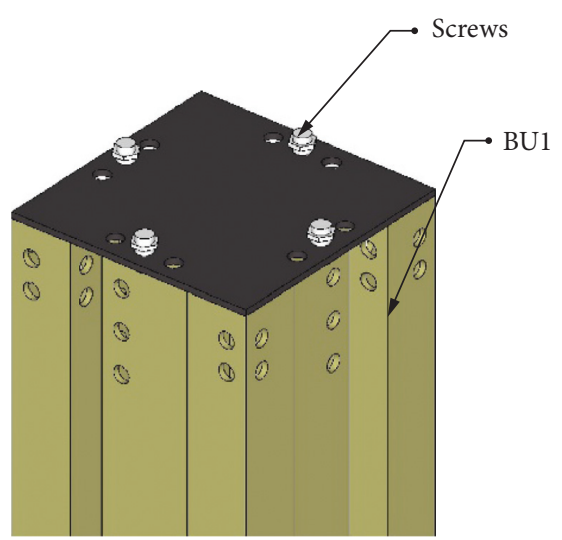

(a)

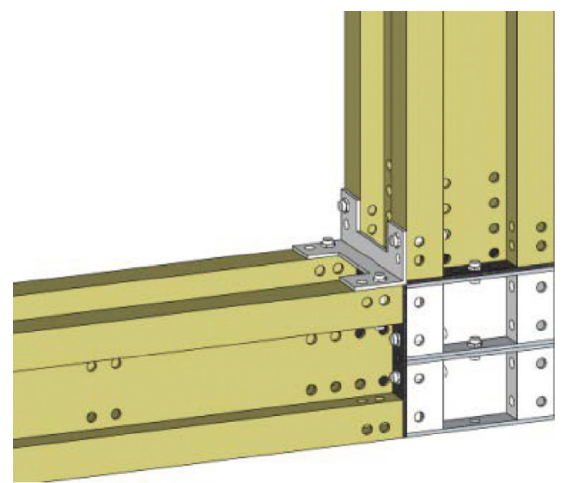

(c)

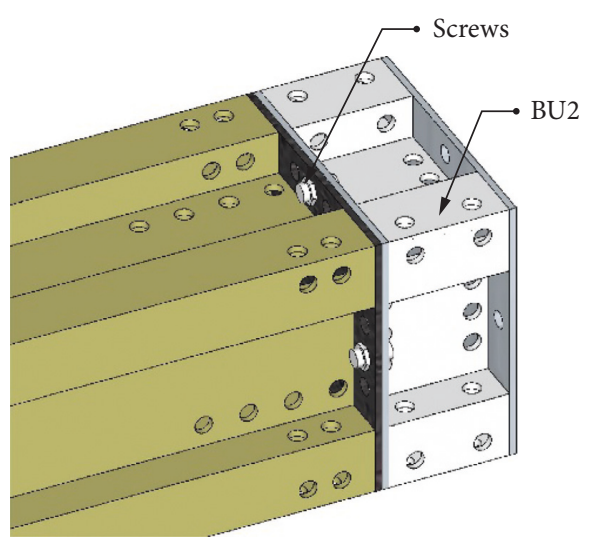

(b)

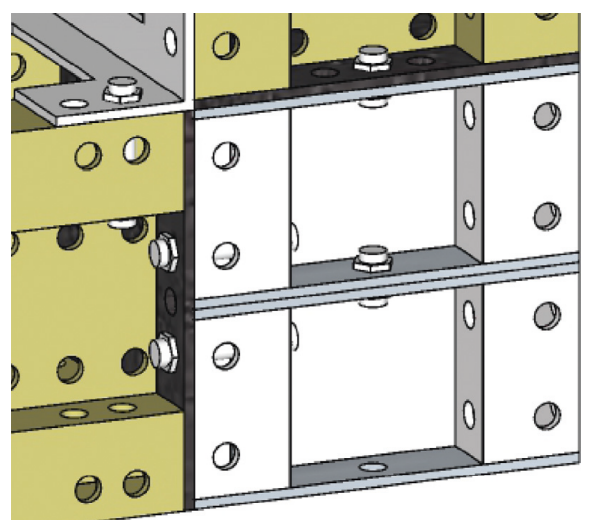

(d)

Figure 8: Connection of different basic units using mechanical fasteners. (a) Screws and BU1, (b) connection of BU1 and BU2, (c) orthogonal connection of BU1 and BU2 (2 units of BU2), and (d) detail of the orthogonal connection. 


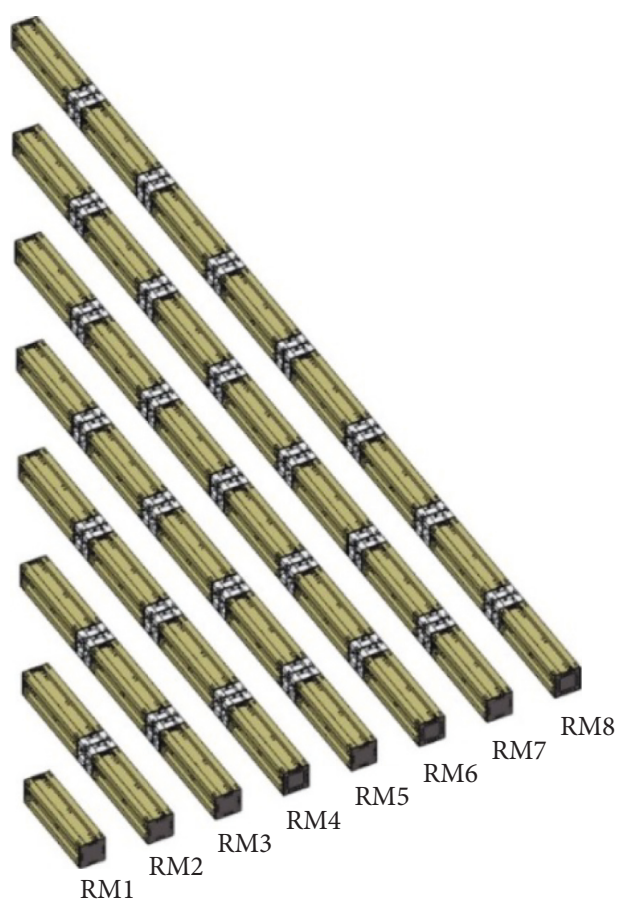

FIGURE 9: Modulated series of the 10 resistant members proposed by the flexible structural system (RMn): RM1, RM2, RM3, RM4, RM5, RM6, RM7, and RM8.

(i) Holes in the end plates of the basic units

(ii) Holes in the profiles for the Global System of Industrialized Construction

(iii) Framing square for orthogonal structural connection

(iv) Through screws with the corresponding nuts

3.3.1. Holes in the End Plates of the Basic Units. The holes in the end plates of the basic units are of great importance to be able to connect the basic units and therefore to form the resistant members.

The basic unit 1 (BU1) presents 3 holes by side that means $3 \times 4=12$ holes by plate and as there are two plates, there will be 24 holes in the BU1.

The basic unit BU2 only has 1 hole by side, which means 8 holes in total for this basic unit.

3.3.2. Holes in the Profiles. As seen in Figure 6, the basic units present several holes along the profile that will allow carrying out the connections among different components by means of through bolts with the corresponding nuts.

As above mentioned, the flexible structural system (FSS) is part of the Global System of Industrialized Construction, and therefore, the proposed structure will have to support and attach the different systems of the building (external covering, roof, installations, etc.), so connections through these holes, distributed in the upper and lower parts of the basic units, are proposed (Figure 6).
These assemblies of industrialized components require to have a significant number of possible connections (initially we do not know "or how many, or where"), and therefore, it is a necessary condition to present a large number of holes. These holes could or could not be used, but their presence guarantees the versatility of the system, similar to the conventional shelving systems.

The holes are distributed over the 4 faces of the profile (Figure 10). The location of these holes does not follow any mathematical relationship but is based on trial and error experiences for each and every connection, over 3D geometric models using the software SketchUp [17]. A special consideration is needed for the components in corners and structural edges that impose their singularity causing an increase in the number of possible connections. The aim of presenting so many holes is to achieve the higher versatility with the elements used by the structural flexible system.

The number of holes for the basic unit 1 (BU1) in the profile can be summarized as follows:

(i) Number of holes by longitudinal side of the profile in the bottom of channel: $8+8+4=20$ holes

(ii) Number of holes by longitudinal side of the profile in the side of channel: $2+2+2+2=8$ holes

(iii) Number of holes by longitudinal side of the profile in the upper face: $2+2+2+2=8$ holes

Then there will be $20+8+8=36$ holes by every longitudinal side of the profile and $36 \times 4=144$ holes in each basic unit 1 (BU1) (Figure 10).

The number of holes in the transverse plates would be $3 \times 4=12$ by plate. As there would be 2 plates by any BU1, the number of holes in the transverse plates would be $12 \times 2=24$ holes. Adding all the described holes, the total number of them by each basic unit 1 would be $144+24=168$.

In the same way, the number of holes can be obtained for every basic unit 2 (BU2), and the result would be 40 holes by any of them.

It is important to keep the same diameter in all these holes as it gives greater versatility. Therefore, the proposal is that all these holes have a diameter of $8 \mathrm{~mm}$.

The distance between holes was decided taking into account the possible connections over 3D geometrical models using the software SketchUp [17]. The result was to propose two different distances depending on the holes location.

For those holes in the bottom of the longitudinal channel, the proposed distances among holes axis is $20 \mathrm{~mm}$.

In case of holes on the channel sides and the upper sides, the proposed distance is $15 \mathrm{~mm}$.

3.3.3. Unique Framing Square. In order to achieve the different orthogonal joints, a new industrialized component that was named unique framing square is needed, which turns out to be as a simple angle cleat profile, in which a series of conveniently distributed holes have been drilled.

The joint is performed by means of through screws that connect the framing squares to the basic units and are fixed with the corresponding tightening nuts. The framing squares 


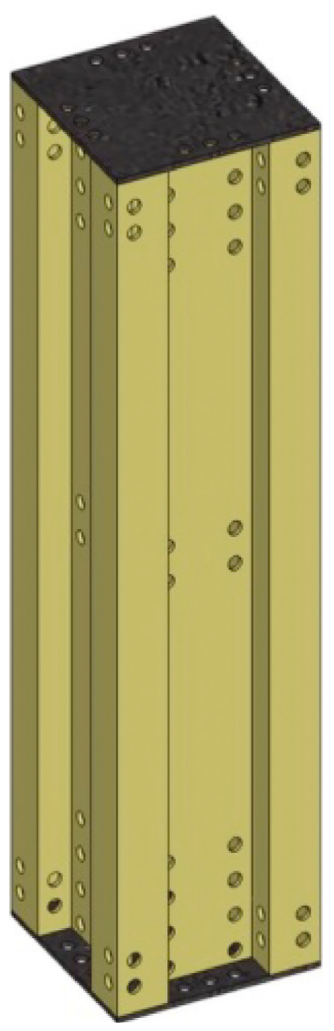

(a)

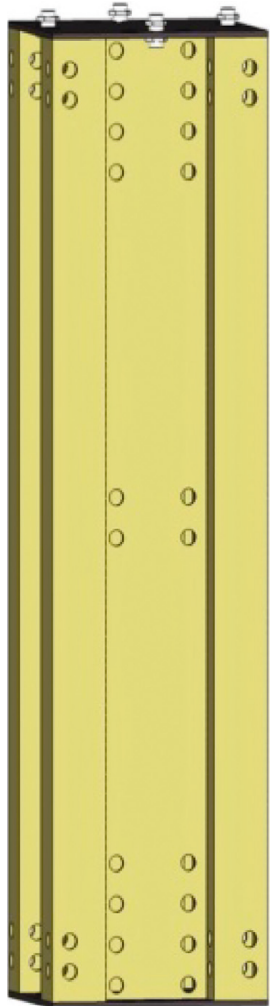

(b)

FIgURe 10: Holes for connections in basic units 1 (BU1). Total number of holes: 168. (a) Holes in BU1 (side view); (b) holes in BU1 (front view).

are connected by four screws (two by leg) in alternative positions in order not to interfere two perpendicular directions of them as can be seen in Figure 11. Figure 11(a) presents the dimensions of the framing square, while Figures 11(b), 11(c), and 11(d) show different type of joints and views using the unique framing square.

3.3.4. Screws. The proposed geometry allows an easy coupling among the different basic units (BUi) and therefore among the resistant members (RMn). This means an advantage for the flexible structural system since the type of joint is unique and all the assemblies are made in the same way.

The proposed joint allows it to behave as semirigid with different stiffness depending on the wall thickness adopted for the basic units and the position of the joint in the structure as proved below. However, the joint characterization and other design possibilities are not going to be considered in detail in the present work, since it is the topic of another research line now in progress.

The system requires a screwed bar with a diameter of $8 \mathrm{~mm}$ with two nuts and two different lengths, depending on the pieces to be joined (Figure 12). They are proposed on Class 8.8 not preloaded, with a nominal yield strength $f_{\mathrm{yb}}=640 \mathrm{~N} / \mathrm{mm}^{2}$ and nominal ultimate tensile strength $f_{\mathrm{ub}}=800 \mathrm{~N} / \mathrm{mm}^{2}$. The calculations proved that these proposed screws have enough shear, tension, and bearing resistance to verify the limit states according to the code of design [18].
Therefore, the flexible structural system requires two types of screws.

Short screw is $8 \mathrm{~mm}$ in diameter and $20 \mathrm{~mm}$ length. It is used to connect the components in the longitudinal direction, for example, to connect the basic units to form a resistant bar (Figures 8 and 12).

Long screw: $8 \mathrm{~mm}$ in diameter and $50 \mathrm{~mm}$ length. It is mainly used to connect the orthogonal components using at the same time a framing square (Figures 11 and 12).

3.4. Frames. The flexible structural system is based on the formation of structural frames with an orthogonal geometry, using the previously described resistant members. A frame is going to be constituted by two resistant members arranged in a vertical position that are named "columns" and two resistant members placed in horizontal position named "beams". The columns will have a constant length while the beam may have a variable length.

In order to simplify the system and for an easy and immediate application, an initial hypothesis is considered that consists of establishing the height with a constant dimensional coordination value of $30 \mathrm{M}$. Therefore, all frames will have this height.

The constant height of any frame corresponds to the value established for the column. This column will be formed by the resistant member 5 (RM5) plus two basic units (UB2) connected at each end. Therefore, the column will present a height of $3120 \mathrm{~mm}$ (Figure 13). 


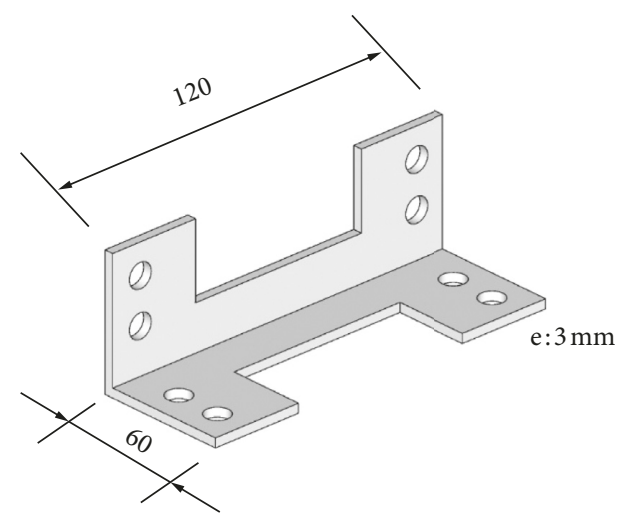

(a)

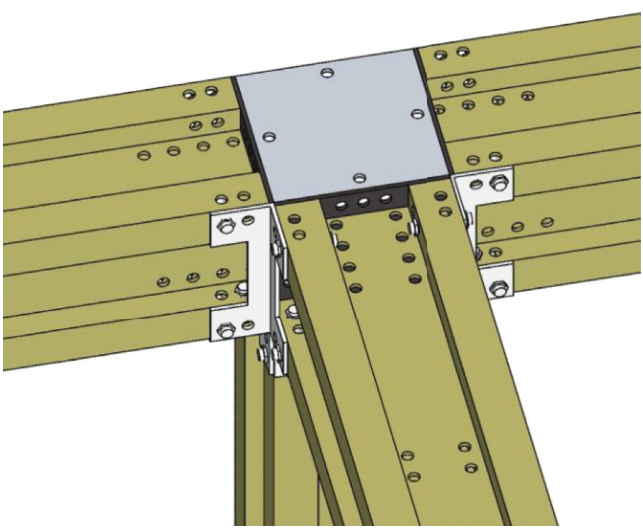

(c)

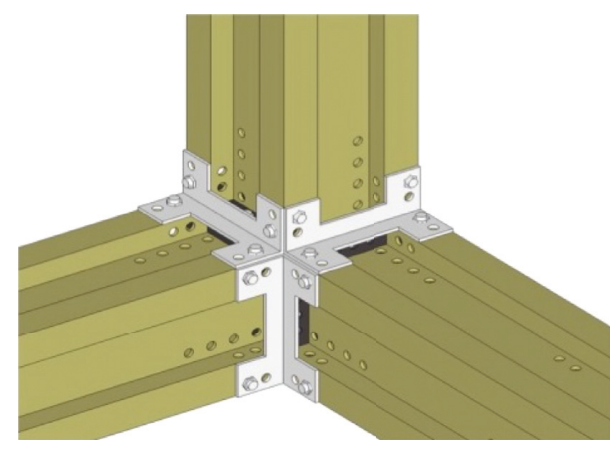

(b)

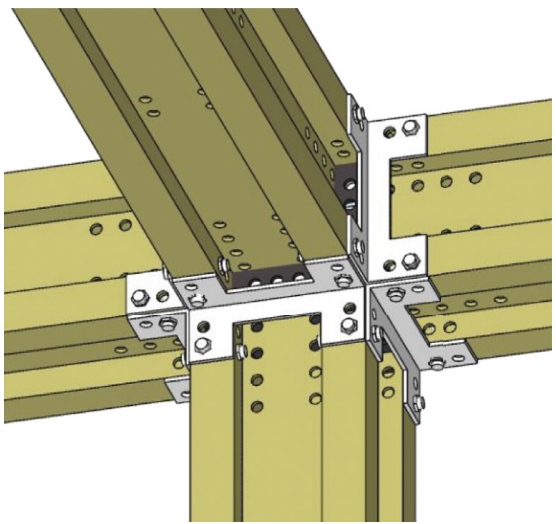

(d)

FIGURE 11: Joints performed by means of the unique framing square. (a) Unique framing square, (b) assembly by the framing squares, (c) top view of a $3 \mathrm{D}$ joint, and (d) bottom view of a 3D joint.

$$
\text { Column length }=2(\text { BU2 })+\text { RM5 }+2(B U 2)=3120 \mathrm{~mm} .
$$

Once there is a column with a constant height, it is possible to start generating the different frames that will allow generating the system. To form the frames, a pair of resistant members (RMn) with the required dimension from the 8 of them above described in Figure 9 are taken as beams on top and bottom of the frame and are connected to two columns as shown in Figure 14.

The adopted name is related to the coordination dimension of the beam to be placed, since it is the only variable to consider. So, we start by putting the letter " $F$ " corresponding to the frame and then the modular coordination dimension $6 \mathrm{M}, 12 \mathrm{M}, \ldots, 48 \mathrm{M}$.

Now, it is possible to start generating frames that the system allows, in such a way that if the resistant member 1 (RM1) is used as beam, the frame will have a span free of $480 \mathrm{~mm}$ and it is named F6M. The frame F6M is composed by two columns and two resistant members type RM1. In this same way, the rest of frames can be formed. So the system allows the formation of 8 different frames that are listed below (Figure 15)

(i) $\mathrm{F} 6 \mathrm{M}=2$ columns $+2 \mathrm{RM} 1=\operatorname{span} 480 \mathrm{~mm}$. Coordination dimension $=600 \mathrm{~mm}$ (ii) $\mathrm{F} 12 \mathrm{M}=2$ columns $+2 \mathrm{RM} 2=$ span $1080 \mathrm{~mm}$. Coordination dimension $=1200 \mathrm{~mm}$

(iii) $\mathrm{F} 18 \mathrm{M}=2$ columns $+2 \mathrm{RM} 3=$ span $1680 \mathrm{~mm}$. Coordination dimension $=1800 \mathrm{~mm}$

(iv) $\mathrm{F} 24 \mathrm{M}=2$ columns $+2 \mathrm{RM} 4=$ span $2280 \mathrm{~mm}$. Coordination dimension $=2400 \mathrm{~mm}$

(v) $\mathrm{F} 30 \mathrm{M}=2$ columns $+2 \mathrm{RM} 5=$ span $2880 \mathrm{~mm}$. Coordination dimension $=3000 \mathrm{~mm}$

(vi) $\mathrm{F} 36 \mathrm{M}=2$ columns $+2 \mathrm{RM} 6=\operatorname{span} 3480 \mathrm{~mm}$. Coordination dimension $=3600 \mathrm{~mm}$

(vii) $\mathrm{F} 42 \mathrm{M}=2$ columns $+2 \mathrm{RM} 7=$ span $4080 \mathrm{~mm}$. Coordination dimension $=4200 \mathrm{~mm}$

(viii) $\mathrm{F} 48 \mathrm{M}=2$ columns $+2 \mathrm{RM} 8=\operatorname{span} 4680 \mathrm{~mm}$. Coordination dimension $=4800 \mathrm{~mm}$

\section{Generation of Structural Schemes with the Flexible Structural System (FSS)}

From the two-dimensional frames described in the previous section, it is time now to generate structural schemes associated with volumes. To achieve this, the frames must be connected in order to form a 3D orthogonal structure.

The aim is to obtain a diaphanous volume as useful living space, supported by a simple, reliable, and durable structure. 

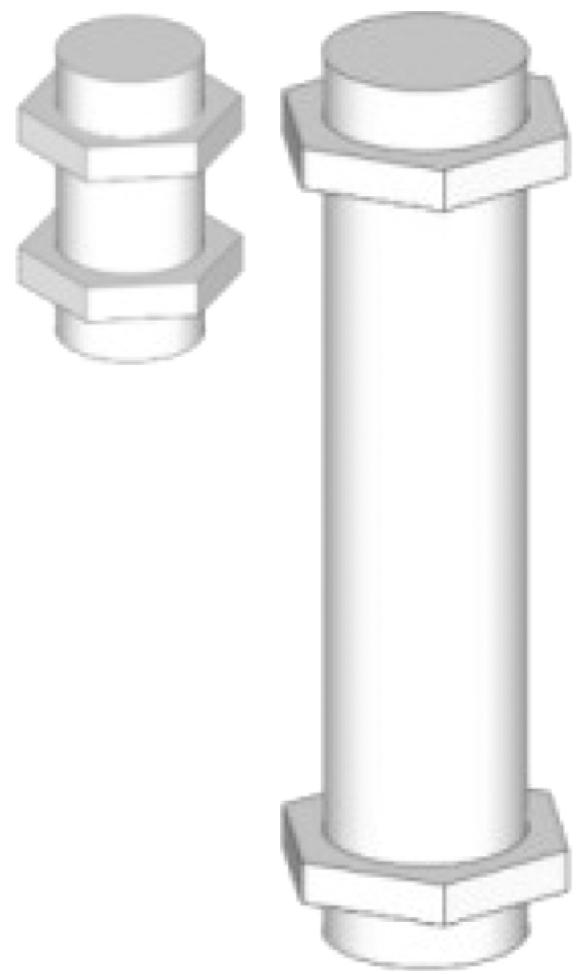

(a)

(b)

Figure 12: Screw and tightening nuts. (a) Short screw: $8 \mathrm{~mm}$ in diameter and $20 \mathrm{~mm}$ length; (b) long screw: $8 \mathrm{~mm}$ in diameter and $50 \mathrm{~mm}$ length.

To achieve this goal, two types of frames are going to be established:

(i) Wall Frames. They present a structural distribution around the diaphanous volume and are responsible for the load carrying through vertical planes.

(ii) Beam Frames. They are responsible to cover the span and then for the generation of diaphanous internal space.

These frames would not be independent of each other but would share the same elements of support or columns. These two types of frames would be distributed orthogonally, one with regard to the others. The main difference between wall frames and beam frames is their placement as they are distributed orthogonally.

Adopting a Cartesian 3D reference system (axis $X, Y$, and $Z$ ) as shown in Figure 16, the wall frames would be located around the perimeter, and in this case, they are parallel to plane $X Z$. These wall frames are not totally individual but they form series that share columns. Then, the vertical structural scheme of the diaphanous volume is already available.

Later, orthogonal beams are positioned on the wall frames, in such a way that they allow obtaining the diaphanous volume. These beams are placed on the columns that belong to the wall frames. It is clear that these beam

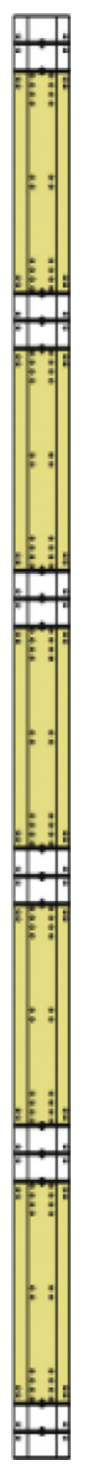

FIgURE 13: Column with a total length of $3120 \mathrm{~mm}$.

frames are those that provide the diaphanous volume and therefore the useful housing space sought.

This orthogonal distribution of frames helps to set out a generation of volumes in a systematic way. In Figure 16, it can be observed that for two parallel planes $X Z$, three continuous wall frames have been positioned corresponding to frames denoted as F18M, F18M, and F12M. Also, resistant members RM6 have been positioned as beams in the bottom and the top planes, forming in this way the beam frames corresponding to F36M. The beam frames share the columns with the wall frames.

In Figure 17, it can be observed the total diaphanous volume generated. The system allows generating volumes in any orthogonal direction.

(i) The wall frames positioned are as follows: 2(F18M), 2(F18M) y 2(F12M) in two planes parallel to XZ.

(ii) The beam frames are as follows: $4(\mathrm{~F} 36 \mathrm{M})$ in four planes parallels to $Y Z$. 


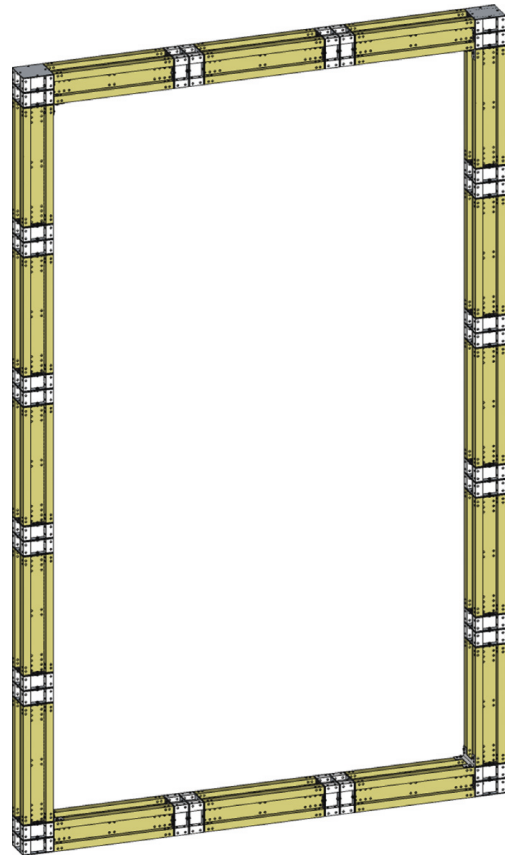

Figure 14: Frame F18M; span $1680 \mathrm{~mm}$; modular coordination dimension: $1800 \mathrm{~mm}$.

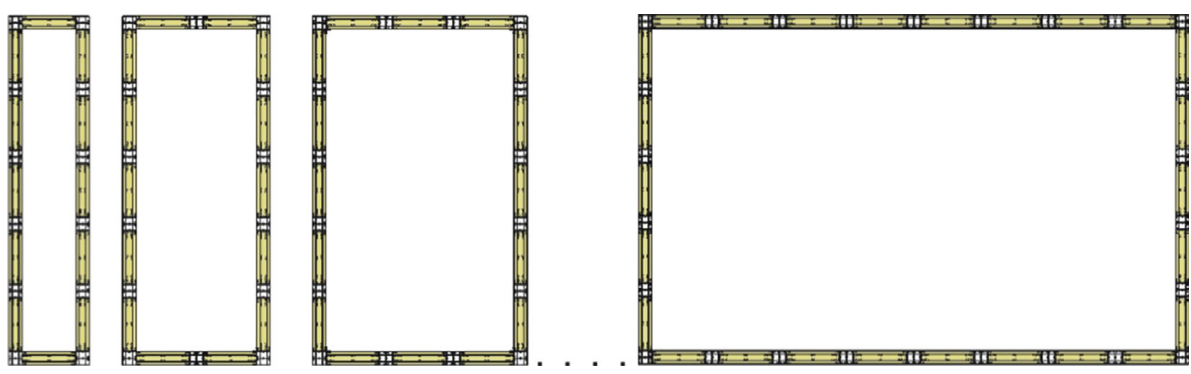

Figure 15: Series of beam frames F6M, F12M, F18M, ..., F48M.

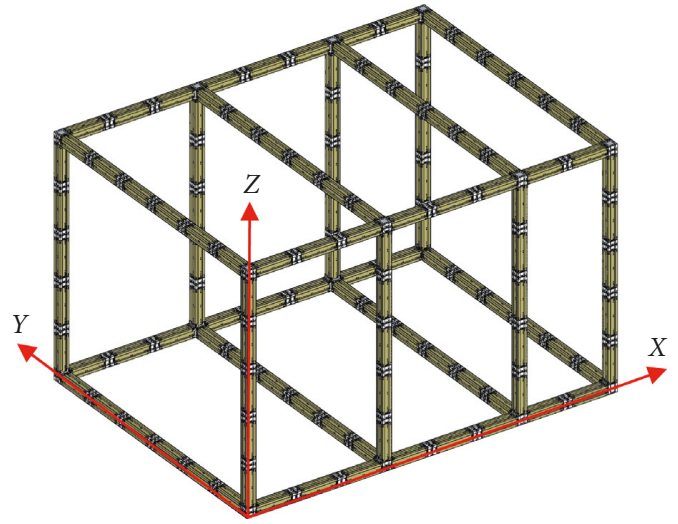

Figure 16: Volume generated by wall frames in 2 planes parallel to $X Z$ plus beam frames in 4 planes parallel to $Y Z$.

4.1. Wall Frames Used by the FSS. As said above, the wall frames are the structural components that are distributed on the perimeter of the required diaphanous volume. They are similar to the load bearing walls of the traditional constructions.
The flexible structural system proposes the use of only the three types of wall frames of the series, i.e., F6M, F12M, and F18M (Figure 18).

It is important to note that the addition of wall frames does not imply the repetition of adjacent columns. When two columns coincide, the FSS proposes the placement of a single column (Figure 17). This is possible due to the flexibility of the proposed system since it allows the positioning of these elements according to a continuous addition. This continuous addition has the limitation of the greater wall frame that corresponds with the F18M.

Type of wall frames:

$$
\begin{aligned}
& \mathrm{F} 6 \mathrm{M}=600 \mathrm{~mm} \text { coordination dimension } \\
& \mathrm{F} 12 \mathrm{M}=1200 \mathrm{~mm} \text { coordination dimension } \\
& \mathrm{F} 18 \mathrm{M}=1800 \mathrm{~mm} \text { coordination dimension }
\end{aligned}
$$

4.2. Available Beam Frames in the FSS. As said above, when the wall frames are connected by beams (formed by resistant member (RMn)), the so-called beam frame appears and it is possible to obtain any required diaphanous space. The 


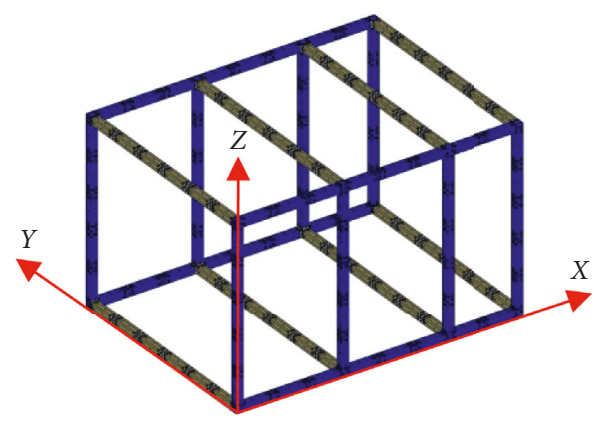

(a)

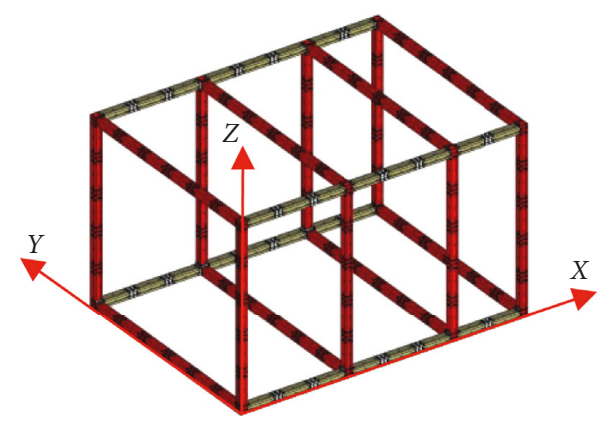

(b)

FIGURE 17: Wall frames and their corresponding orthogonal beam frames. (a) Wall frames in two planes parallel to XZ: 2(F18M), 2(F18M) $y$ 2(F12M) (blue colour), (b) beam frames in two planes parallel to $Y Z$ : 4(F36M) (red colour).
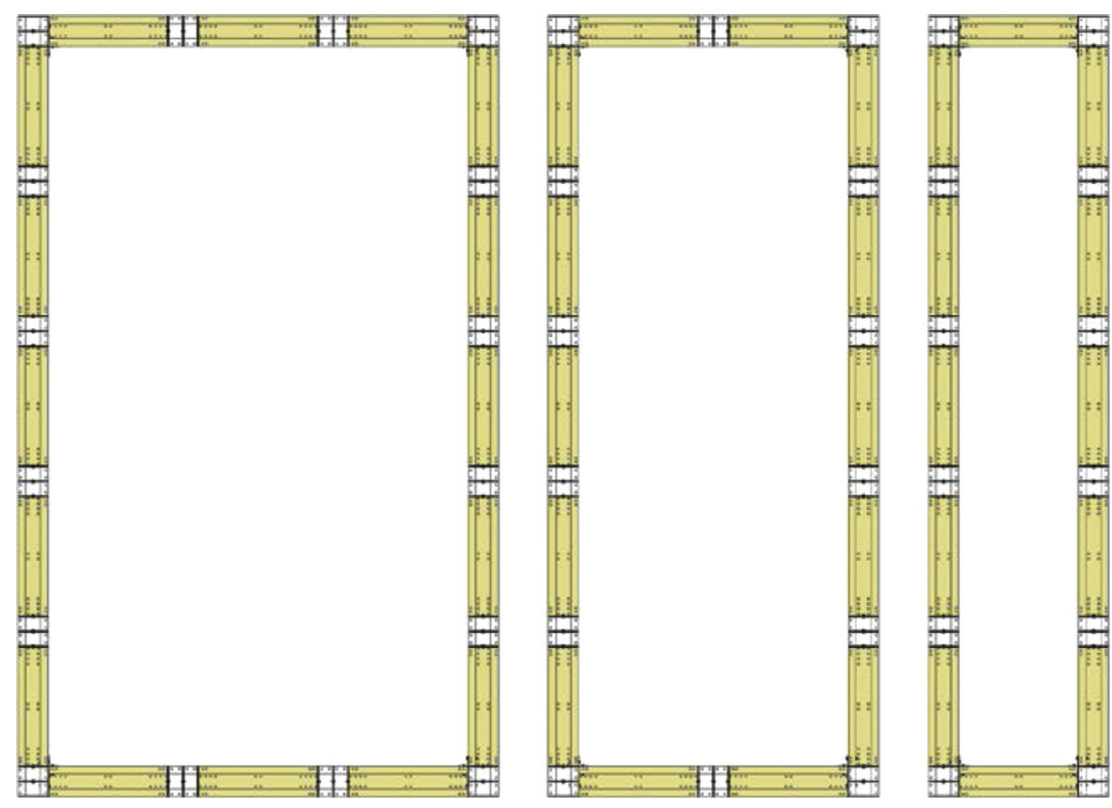

FIGURE 18: Wall frames: F18M, F12M, and F6M.

positioning of the resistant members (RMn) corresponds with the closest column from the wall frame.

The proposed beam-column connections are made using mainly but not only framing squares. The beam-column connections for the wall frames (section 4.1) also include 4 screws connecting the end plate of the beam to the column (Figures 8(c) and Figure 8(d)). In the 3D connections between beam frames and wall frames, three framing squares are used for the internal main frames (top and bottom views in Figure 11) and two squares plus two screws on the end plates for the external main frames.

Although it will be necessary to verify experimentally with a prototype the behaviour of the structural system, including the joints, the initial calculations carried out below indicate that the joints remain safe to withstand the expected loads.

The calculations also show that beams with a maximum length of 4.8 meters provide enough in-plane flexural resistance. Due to the hollow cross section, there will be no concerns regarding the lateral torsional buckling.
Furthermore, some shorter components that connect parallel beams and the floor joists will provide enough horizontal stability.

The possible wall frames to be used corresponds to the full range of resistant members (RMn) above described (Figure 15). Therefore, the types of beam frame proposed are 10:
(i) $\mathrm{F} 6 \mathrm{M}=600 \mathrm{~mm}$ coordination dimension
(ii) $\mathrm{F} 12 \mathrm{M}=1200 \mathrm{~mm}$ coordination dimension
(iii) $\mathrm{F} 18 \mathrm{M}=1800 \mathrm{~mm}$ coordination dimension
(iv) $\mathrm{F} 24 \mathrm{M}=2400 \mathrm{~mm}$ coordination dimension
(v) $\mathrm{F} 30 \mathrm{M}=3000 \mathrm{~mm}$ coordination dimension
(vi) $\mathrm{F} 36 \mathrm{M}=3600 \mathrm{~mm}$ coordination dimension
(vii) $\mathrm{F} 42 \mathrm{M}=4200 \mathrm{~mm}$ coordination dimension
(viii) $\mathrm{F} 48 \mathrm{M}=4800 \mathrm{~mm}$ coordination dimension

Finally, it can be seen how the general structural scheme for a diaphanous volume is established. In Figure 19, it is possible to see the following values: 


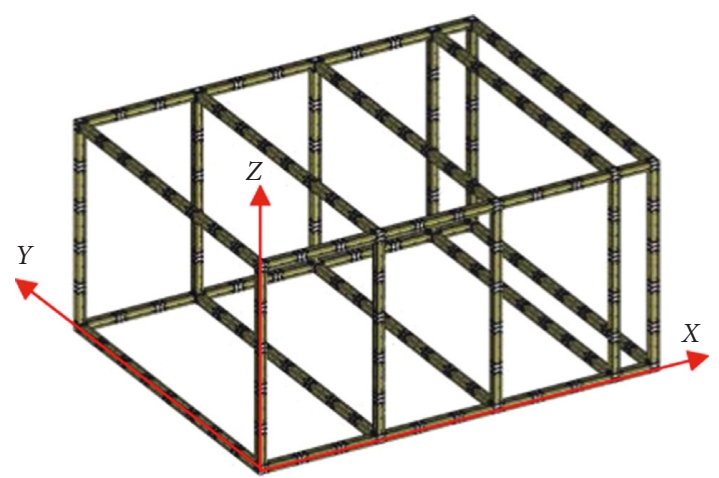

Figure 19: Structural scheme for a diaphanous volume.

Diaphanous volume: $\mathrm{DV}$ (axes $X, Y$, and $Z$ ) $=\mathrm{DV}$ $(6000 \mathrm{~mm} \times 4800 \mathrm{~mm} \times 3000 \mathrm{~mm})=86.42 \mathrm{~m}^{3}$

Wall frames: $(3(\mathrm{~F} 18 \mathrm{M})+1(\mathrm{~F} 6 \mathrm{M})) \times 2$ (parallels to the $X Z$ plane).

Beam frames: 5(F48M) (parallels to the $Y Z$ plane)

4.3. Reliability Analysis of the Structure. As above commented to optimize the structural design by reducing the number of different components, the system only allows the variation of the thickness of the proposed profile. Some calculations have been carried out using the general-purpose finite element software Ansys Workbench to probe that the proposed profiles are safe and adequate from a structural point of view. As a first step, two 3D joints and other two plane (2D) joints, corresponding to the intermediate and the top floors in a two-storey building configuration, were modelled separately for the both proposed thicknesses $(2 \mathrm{~mm}$ and $3 \mathrm{~mm}$ ) to obtain their beam-column rotational joint stiffness. The numerical models were performed for a nominal steel S275. Table 1 presents the main mechanical properties of the modelled cross sections.

Figure 20 presents, as an example, four of the eight joints modelled showing their meshing. Figures 20(a) and 20(c) show a pair of $3 \mathrm{D}$ joints at the top and the intermediate levels. These models include wall frames and beam frames. Figures 20(b) and 20(d) show the two plane joints at the top and the intermediate levels. In this case, the bracing members that form the wall frames and that connect the main 2D frames of the structure are not included.

Figure 21 presents the moment-rotation curves for the eight joints modelled and grouped by their wall thickness. Figure 21(a) shows the curves for $3 \mathrm{~mm}$ thickness, and Figure 21(b) shows the curves for the same type of joints in case of $2 \mathrm{~mm}$ thickness. In these graphics also, the limits for nominally rigid and nominally pinned joints according to EC3 Part 1.8 [19] were plotted. From these figures, it can be concluded that in most cases, the joints behave as semirigid.

The obtained joint rotational stiffness from the previous calculations was used then in a second step to prove the reliability of the structure. A typical main $2 \mathrm{D}$ frame with two storeys as the one that can be seen in Figure 22 was modelled using finite element analysis to obtain the stress state (Figure 22(a)) in the ultimate limit state (ULS) and
TABLE 1: Mechanical properties of the cross sections.

\begin{tabular}{lccc}
\hline $\begin{array}{l}\text { Wall } \\
\text { thickness }\end{array}$ & $\begin{array}{c}\text { Area } A \\
\left(\mathrm{~mm}^{2}\right)\end{array}$ & $\begin{array}{c}\text { Moment of } \\
\text { inertia } \\
I_{\mathrm{yy}}=I_{\mathrm{zz}}\left(\mathrm{mm}^{4}\right)\end{array}$ & $\begin{array}{c}\text { Warping } \\
\text { modulus } \\
I_{\mathrm{w}}\left(\mathrm{mm}^{6}\right)\end{array}$ \\
\hline$t=2 \mathrm{~mm}$ & 1264 & $2.2487 e+6$ & $1.8998 e+8$ \\
$t=3 \mathrm{~mm}$ & 1884 & $3.2834 e+6$ & $2.7029 e+8$ \\
\hline
\end{tabular}

directional deformations (Figure 22(b)) in the serviceability limit state (SLS). The loads, materials, and dimensions considered in the calculations are as follows:

(i) Span: 4.8 meters

(ii) Height: 3 meters

(iii) Live loads corresponding to a typical residential building: $2 \mathrm{kN} / \mathrm{m}^{2}$

(iv) Additional concentrated live load: $2 \mathrm{kN}$

(v) Wind $1 \mathrm{kN} / \mathrm{m}^{2}$

(vi) Snow $1 \mathrm{kN} / \mathrm{m}^{2}$

(vii) Self weight $0.6 \mathrm{kN} / \mathrm{m}^{2}$

(viii) Nominal steel S275 (yield limit $f_{\mathrm{y}}=275 \mathrm{~N} / \mathrm{mm}^{2}$ )

The maximum combined stress was $268.73 \mathrm{~N} / \mathrm{mm}^{2}$ lower than the yield limit. Also the maximum deflection in the middle of the span was $15.795 \mathrm{~mm}$ that was lower than the ordinary limit $(\mathrm{L} / 250=19.2 \mathrm{~mm})$ typically considered in the Eurocode 3 Part 1. [18].

The result was that the two defined thicknesses of $2 \mathrm{~mm}$ and $3 \mathrm{~mm}$ are adequate according to the colour code indicated in Figure 7. Nevertheless, the launching of this system would require having simple structural design software that depending on the different building conditions, the proposal of the resistant members would be obtained.

4.4. Simple Application Example of the Flexible Structural System (FSS). We need constructing the structural scheme for a diaphanous volume, with the following values:

(i) Length: 4.80 meters

(ii) Width: 3.6 meters

(iii) Height: 3.0 meters wide:

Diaphanous volume: $\mathrm{DV}($ axes $X, Y$, and $Z)=\mathrm{DV}$ $(4.8 \mathrm{~m} \times 3.6 \mathrm{~m} \times 3.0 \mathrm{~m})$.

Likewise, this volume is placed at a ground height of at least 0.48 meters.

We need to know

How can we organize a possible structural scheme for this diaphanous volume?

How many industrialized elements are we going to need?

Solution:

DV $(4.8 \mathrm{~m} \times 3.6 \mathrm{~m} \times 3 \mathrm{~m})=\mathrm{DV} \quad(X, Y, Z)=\mathrm{DV}$ (48M, 36M, 30M)

Small lower supports: $1(\mathrm{UB} 1)+1(\mathrm{UB} 2)$ 


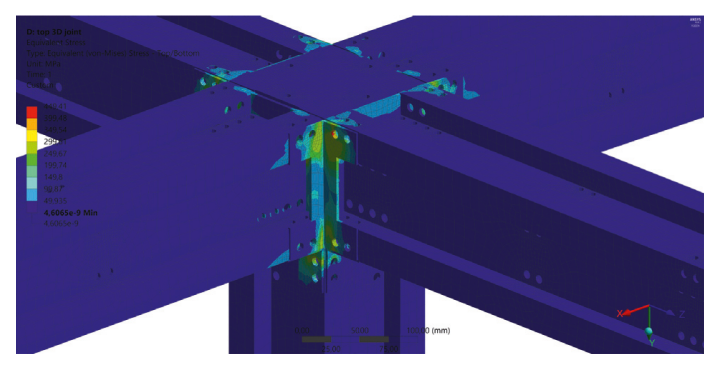

(a)

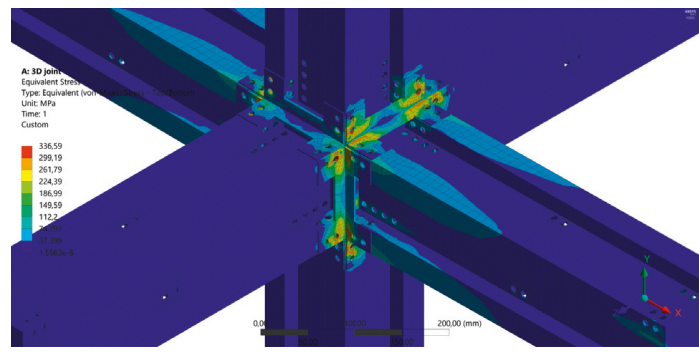

(c)

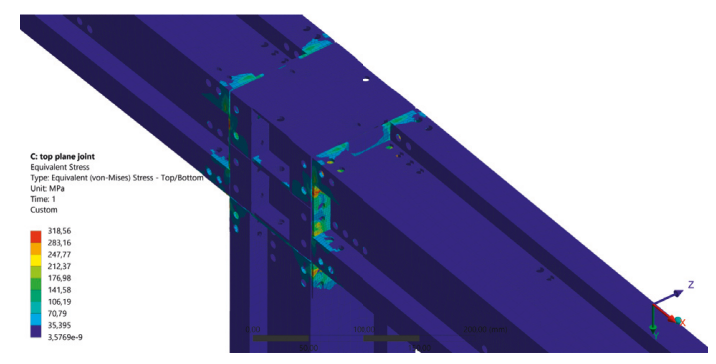

(b)

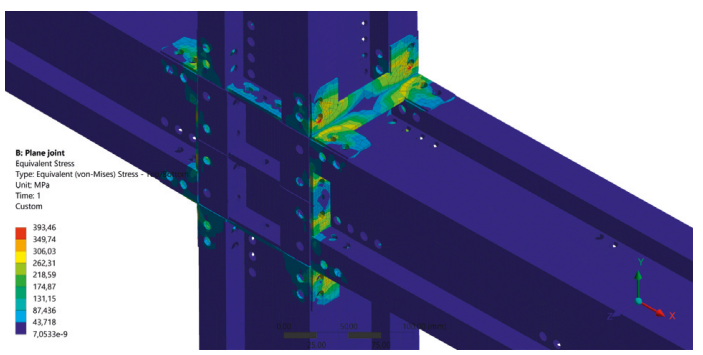

(d)

Figure 20: FEM models for 3D and plane joints. (a) Top 3D joint, (b) top plane joint, (c) intermediate 3D joint, and (d) intermediate plane joint.

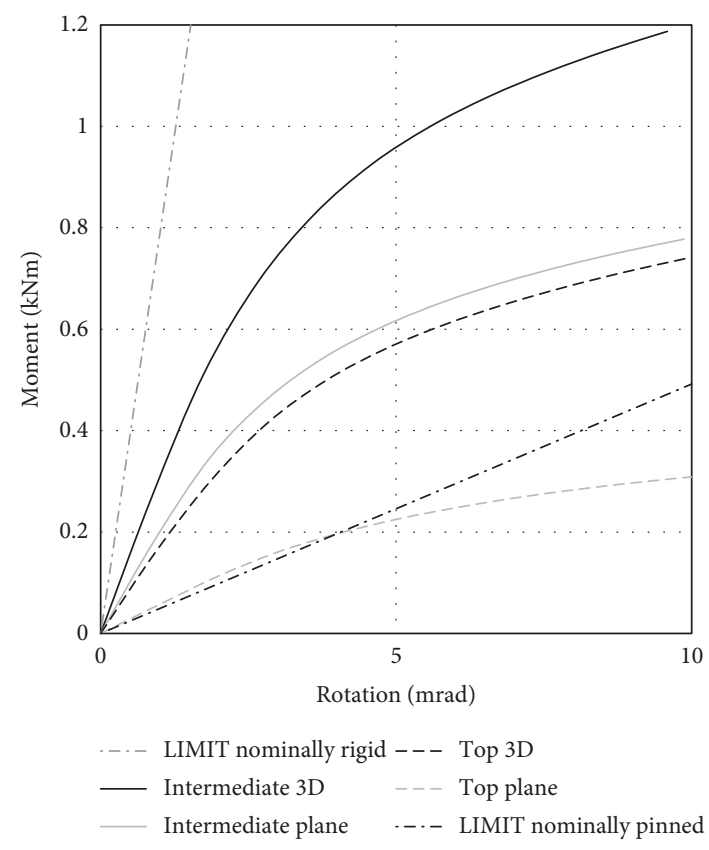

(a)

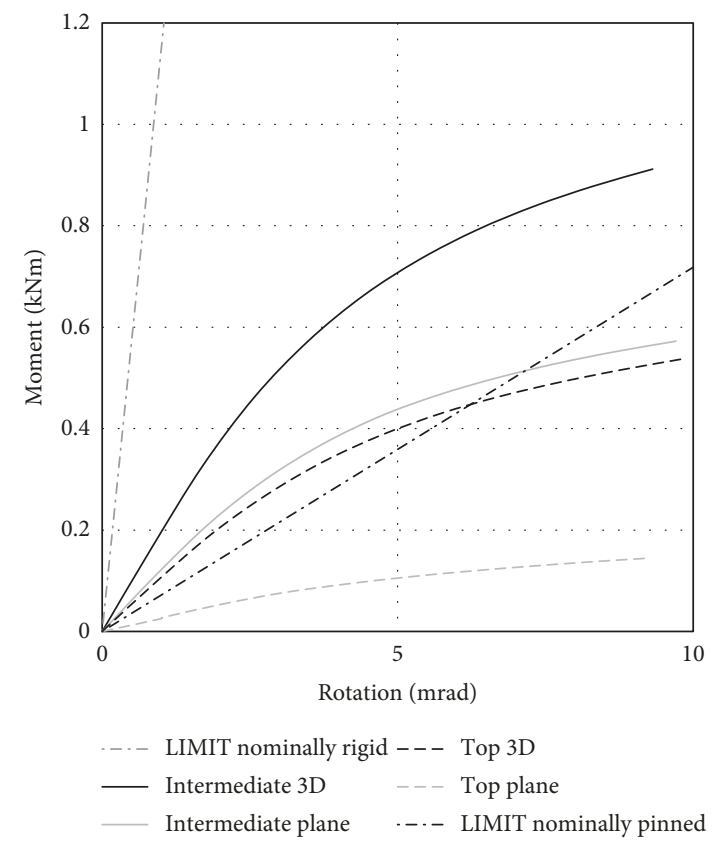

(b)

Figure 21: Moment-rotation curves for 3D and plane joints. Wall thickness (a) $t=3 \mathrm{~mm}$ and (b) $t=2 \mathrm{~mm}$.

Wall frames: $2(\mathrm{~F} 18 \mathrm{M})+1(\mathrm{~F} 12 \mathrm{M})$

Beam frames: $4(\mathrm{~F} 36 \mathrm{M})$

Beam frame $(\mathrm{F} 36 \mathrm{M})=26(\mathrm{UB} 1)+52(\mathrm{UB} 2)+4$ (unique framing square)

Systematic assembly: 1(UB1), 2(UB2), 1(UB1), 2(UB2)...

Number of industrialized elements for DV (48M, 36M, 30M): (i) BU1 green colour $=96$

(ii) BU1 red colour $=48$

(iii) $\mathrm{BU} 2$ green colour $=160$

(iv) BU2 red colour $=96$

(v) Unique framing square $=84$

The solution of structural scheme for this diaphanous volume can be seen in Figure 23 and in Figure 24, with the 


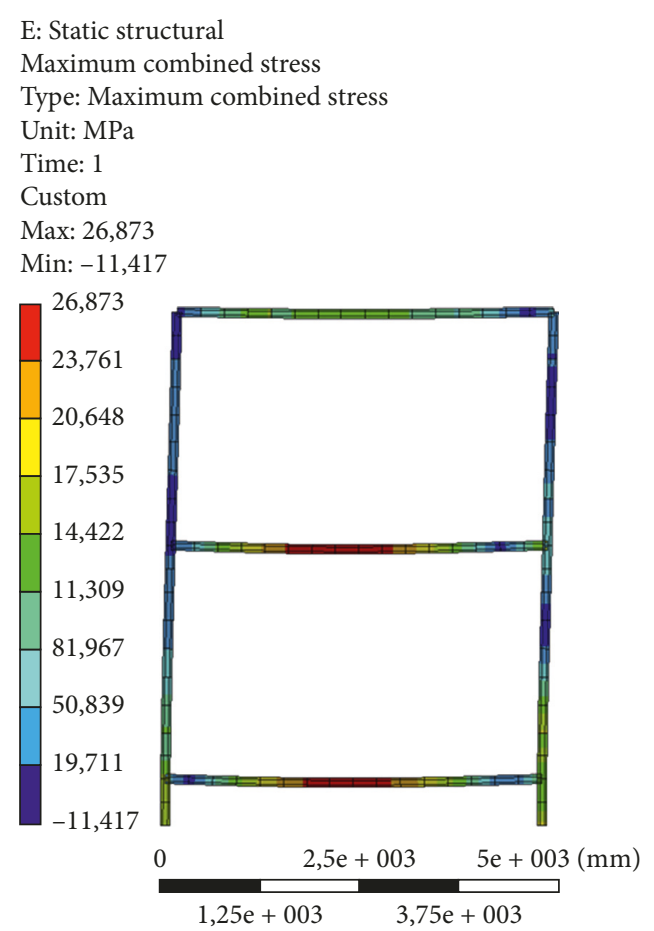

(a)
E: frame SLS

Directional deformation

Type: Directional deformation (Y axis)

Unit: $\mathrm{mm}$

Global coordinate system

Time: 1

Custom

Max: 0

Min: $-15,795$

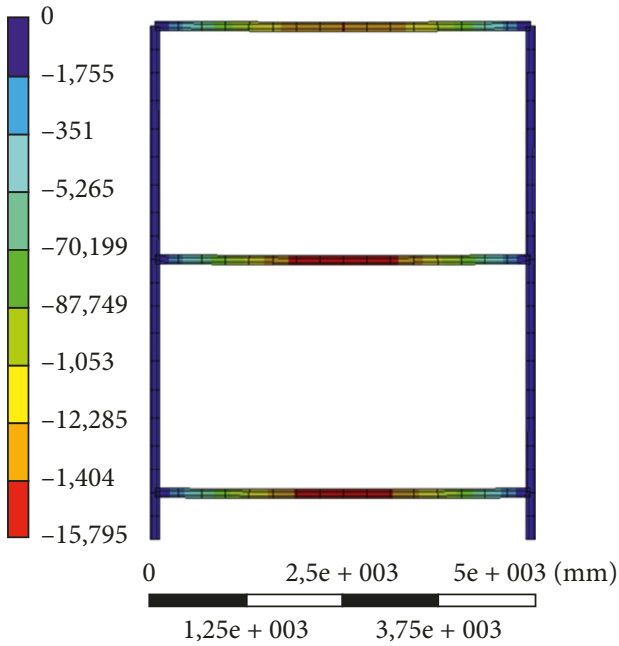

(b)

FIGURE 22: Results in a main 2D frame with plane joints. (a) Combined stress and (b) directional deformation.

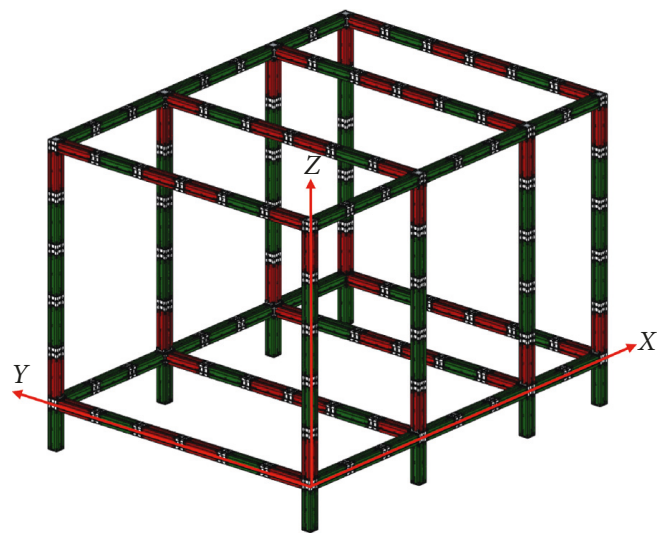

Figure 23: Structural scheme for a diaphanous volume DV $(4.8 \mathrm{~m} \times 3.6 \mathrm{~m} \times 3 \mathrm{~m})$, with all the industrialized elements.

\begin{tabular}{|l|c|c|c|c|c|}
\hline $\begin{array}{c}\text { Element } \\
\text { denomination }\end{array}$ & $\begin{array}{c}\text { BU1, } t=2 \mathrm{~mm} \\
\text { green color }\end{array}$ & $\begin{array}{c}\text { BU1, } t=3 \mathrm{~mm} \\
\text { red color }\end{array}$ & $\begin{array}{c}\text { BU2, } t=2 \mathrm{~mm} \\
\text { green color }\end{array}$ & $\begin{array}{c}\text { BU2, } t=3 \mathrm{~mm} \\
\text { red color }\end{array}$ & $\begin{array}{c}\text { Unique } \\
\text { framing } \\
\text { square }\end{array}$ \\
\hline Figure & & & & & \\
\hline $\begin{array}{c}\text { Number of } \\
\text { elements }\end{array}$ & 80 & 48 & 168 & 48 & 84 \\
\hline
\end{tabular}

Figure 24: Number of industrialized elements needed to generate a structure that allows a diaphanous DV volume $(4.8 \mathrm{~m} \times 3.6 \mathrm{~m} \times 3 \mathrm{~m})$. 
industrialized elements. It can be seen that there are many assemblies with the BUi but very easy and simple to perform in a very systematic way $(1,2,1,2,1,2$, etc.)

\section{Conclusions}

The so-named "flexible structural system" (FSS) is characterized by using only small industrialized components, handled by one person, which exhibit an easy and simple assembly. The system is able to adapt to different orthogonal geometries and presents the necessary flexibility to allow modifications over the structure of the building throughout its life.

The generating process of the structural system is based on different combinations through the so-called structural generating couple with two basic units (BUi) to obtain resistant members (RMn). These resistant members allow building structural frames (F), and finally, the addition of structural frames allows generating diaphanous volumes obtaining the desired structure for the building.

The flexible structural system aims to be systematic and easy to be understood by users.

Furthermore, the FSS has the following characteristics:

(1) The flexible structural system allows generating a great variety of orthogonal structures in a systematic way. Its generation is based on establishing a modulation taking as coordination dimension $6 \mathrm{M}$ $(600 \mathrm{~mm})$.

(2) Any modulated structural configuration can be obtained by the combination of only two elements denoted as basic units. Each one of these basic units presents just 2 thicknesses; therefore, the flexible structural system consists of only 4 basic units.

(3) The total number of different industrialized components is just seven: 4 basic units, 1 unique framing square, and 2 screws with the same diameter and different lengths.

(4) The assembly and disassembly of the system's components require just placing them in the right position and tightening the screws, in quite a large quantity, but in a very systematic and easy way; therefore, it does not require specialized labour.

(5) The system allows the optimization of the structural material with just 2 thicknesses for the profiles. Also, the colours green and red are evident for a simple and easy placement.

(6) The flexible structural system tries to admit the assembly of the rest of the industrialized components of a possible "Global System of Industrialized Construction," whose final objective is the complete construction of a single-family house, or another similar construction, by means of industrialized elements.

(7) The proposed system is easy to transport and store.

(8) The geometrical forms and material for the components of the flexible structural system are conventional, so its manufacture would be simple. In addition, its mass production can allow reduce a lot the market prices.

(9) The proposed connection system using the framing squares allow the joints behave as semirigid [20, 21].

$\begin{array}{ll}\text { Abbreviations } \\ \text { FSS: } & \text { Flexible structural system } \\ \text { BUi: } & \text { Basic units } \\ \text { RMn: } & \text { Resistant members } \\ \text { F: } & \text { Structural frames: wall frames and beam } \\ & \text { frames } \\ \operatorname{DV}(X, Y, Z): & \text { Diaphanous volumes. }\end{array}$

\section{Data Availability}

The data used to support the study are available from the corresponding author upon request.

\section{Conflicts of Interest}

The authors declare that they have no conflicts of interest.

\section{References}

[1] R. E. Smith, Prefab architecture: A guide to modular design and construction, John Wiley \& Sons, Hoboken, NJ, USA, 2010.

[2] M. M. A. Khalfan and T. Maqsood, "Current state of off-site. Manufacturing in Australian and Chinese residential construction," Journal of Construction Engineering, vol. 2014, Article ID 164863, 5 pages.

[3] M. Mokhtariani, M. H. Sebt, and H. Davoudpour, "Construction marketing: developing a reference framework," Advances in Civil Engineering, vol. 2017, Article ID 7548905, 14 pages.

[4] M. Wolf and S. McQuitty, "Understanding the do-it-yourself consumer: DIY motivations and outcomes," AMS Review, vol. 1, no. 3-4, pp. 154-170, 2011.

[5] J. Huizinga, Homo Ludens [HomoLudens], p. 45, Alianza Madrid, Madrid, Spain, 2000.

[6] H. Liang, S. Zhang, and Y. Su, "Evaluating the efficiency of industrialization process in prefabricated residential buildings using a fuzzy multicriteria decision-making method," Mathematical Problems in Engineering, vol. 2017, Article ID 6078490, 12 pages, 2017.

[7] M. I. Norton, D. Mochon, and D. Ariely, "The IKEA effect: when labor leads to love," Journal of Consumer Psychology, vol. 22, no. 3, pp. 453-460, 2012.

[8] J. K. Gershenson, G. J. Prasad, and Y. Zhang, "Product modularity: definitions and benefits," Journal of Engineering Design, vol. 14, no. 3, pp. 295-313, 2003.

[9] A. Kusiak, "Integrated product and process design: a modularity perspective," Journal of Engineering Design, vol. 13, no. 3, pp. 223-231, 2002.

[10] M. Yadollahi, M. Mirghasemi, R. M. Zin, and B. Singh, "Architect critical challenges as a project manager in construction projects: a case study," Advances in Civil Engineering, vol. 2014, Article ID 205310, 2014.

[11] ISO, ISO 1040: 198 Building Construction-Modular Coordination-Multi-Modules for Horizontal Coordinating Dimensions, International Organization for Standardization, Geneva, Switzerland, 1983. 
[12] ISO, ISO 2848: 1984 Building Construction-Modular Coordination-Principles and Rules, International Organization for Standardization, Geneva, Switzerland, 1989.

[13] ISO, ISO 1006: 1983 Building Construction-Modular Coordination-Basic Module, International Organization for Standardization, Geneva, Switzerland, 1983.

[14] J. Mesa, H. Maury, R. Arrieta, L. Corredor, and J. Bris, "A novel approach to include sustainability concepts in classical DFMA methodology for sheet metal enclosure devices," Research in Engineering Design, vol. 29, no. 2, pp. 227-244, 2018.

[15] J. Zhang, G. Xue, H. Du, A. Garg, Q. Peng, and P. Gu, "Enhancing interface adaptability of open architecture products," Research in Engineering Design, vol. 28, no. 4, pp. 545-560, 2017.

[16] X. Liu, A. Zhang, J. Ma, Y. Tan, and Y. Bai, "Design and model test of a modularized prefabricated steel frame structure with inclined braces," Advances in Materials Science and Engineering, vol. 2015, Article ID 291481, 12 pages, 2015.

[17] SketchUp, SketchUp, Formerly Google Sketchup, is a $3 D$ Modeling Computer Program, 2017, http://www.sketchup. com/.

[18] CEN, EN-1993-1-1:2005, Eurocode 3: Design of Steel Structures. Part 1-1, General Rules and Rules for Buildings, European Committee for Standardization, Europe, 2005.

[19] CEN, EN-1993-1-8:2005, Eurocode 3: Design of Steel Structures. Part 1-8, Design of Joints, European Committee for Standardization, Europe, 2005.

[20] D. Lozano, A. Martín, M. Serrano, and M. López, Patent Number ES 2610203 B2, Oficina Española de Patentes y Marcas. Patents and Trademark Office, Madrid, Spain, 2017.

[21] A. Martín, F. Suárez, J. J. Del Coz, A. Lozano, C. González, and M. B. Prendes, "Patent number ES 2568328 B2," Oficina Española de Patentes y Marcas. Patents and Trademark Office, Madrid, Spain, 2016. 


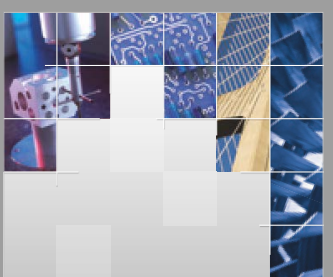

\section{Enfincering}
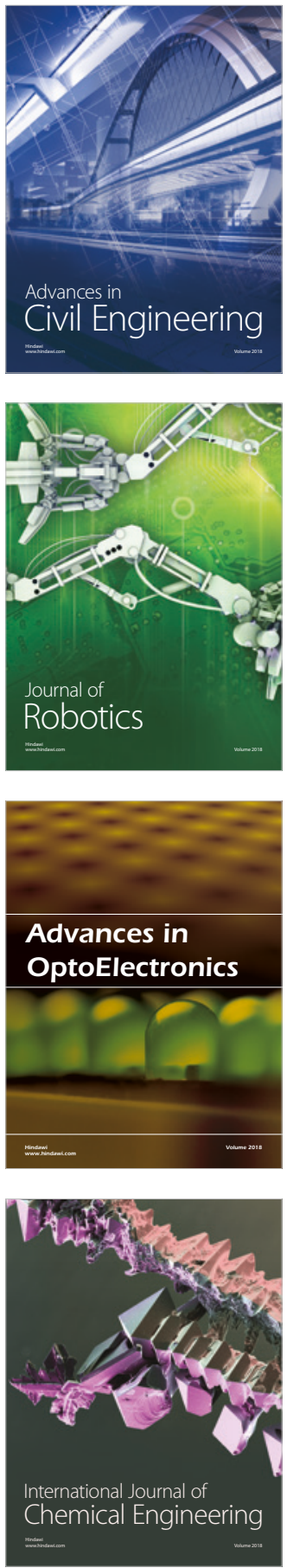

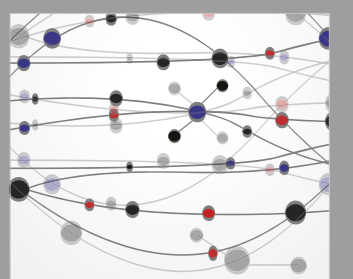

\section{Rotating \\ Machinery}

The Scientific World Journal

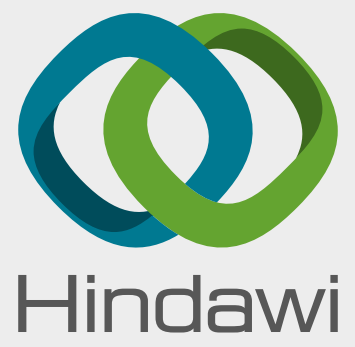

Submit your manuscripts at

www.hindawi.com
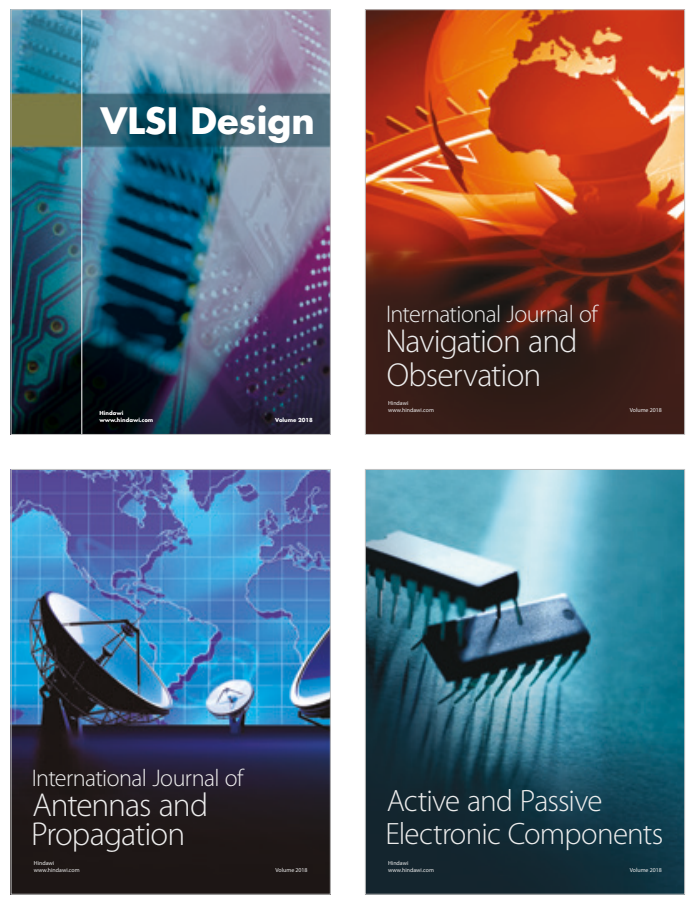
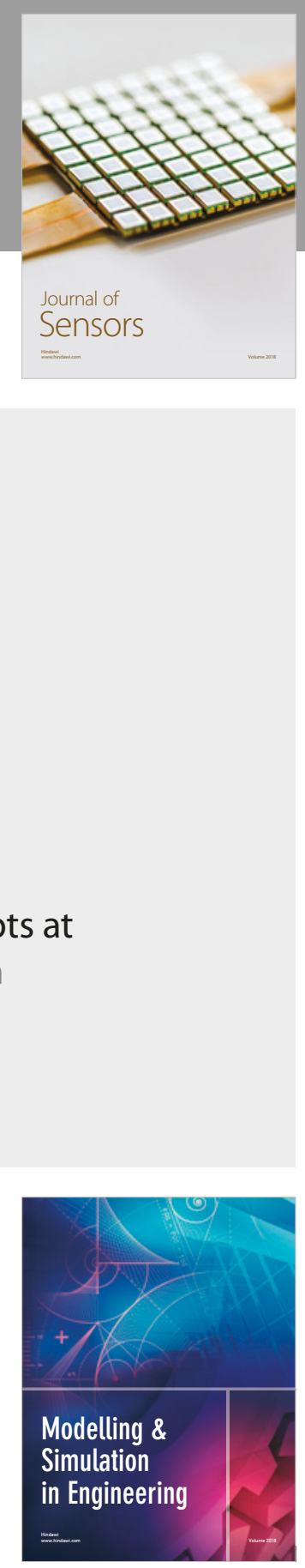

\section{Advances \\ Multimedia}
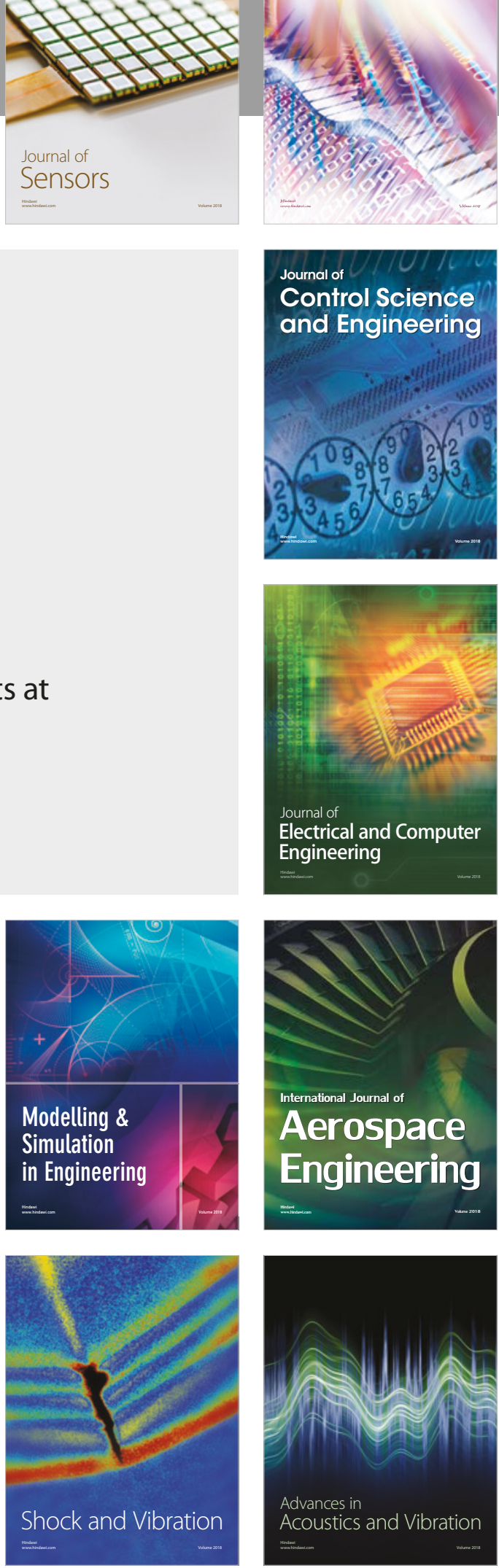